\title{
PELATIHAN MUSIK DAN ORGAN GEREJA HKBP DI HUMBANG HABINSARAN SIBORONG-BORONG
}

\author{
Ance Juliet Panggabean \\ Fakultas Bahasa dan Seni, Universitas HKBP Nommensen
}

\begin{abstract}
Abstrak
Pelatihan Musik gereja dan Organ Gereja HKBP di Humbang Habinsaran Siborongborong adalah salah satu tujuan untuk membantu tim musik dalam pelayanan ibadah di gereja HKBP. Metode dasar yang akan diterapkan di dalam pengabdian masyarakat (PKM) ini adalah metode deskriptif. Selain itu metode pendekatan yang dilakukan metode pelatihan skill/kemahiran untuk teknik bermain musik dan organ, sehingga dihasilkan teknik bermain musik yang baik dan benar. Metode pendampingan dan pengajaran bermain musik dan organ baik secara individu dan kolektif bagi tim musik dengan tujuan agar dapat menumbuhkan rasa kepercayaan diri, seperti tidak canggung, malu, minder akan kekurangan yang dimiliki, sehingga kegiatan bermain musik dapat dilakukan dengan senang hati. Pelaksanaan proses kegiatan pelatihan musik dan organ gereja ini dilakukan dengan metode pengajaran baik secara lisan maupun teori, yang diterapkan melalui metode pendidikan, pelatihan dan pendampingan. Melalui metode pengajaran baik secara lisan, teori dan praktek (demonstrasi) dalam kegiatan pelatihan ini dinilai cukup berhasil. Indikator keberhasilan dapat dilihat dan dievaluasi melalui pertunjukan kecil yang dilakukan secara bersama oleh tim musik dengan song lieder dalam kegiatan terakhir yang dilakukan pada pelatihan.
\end{abstract}

Kata Kunci: Organ, Musik Gereja, Individu, Kolektif

\begin{abstract}
Church Music and Organ Training in Humbang Habinsaran Siborong-borong is one of the goals to help the music team in worship services at the HKBP church. The basic method to be applied in community service is descriptive method. In addition, the approach method used is the skill / skill training method for playing music and organ techniques, so that good and correct music playing techniques are produced. The method of mentoring and teaching playing music and organs both individually and collectively for the music team with the aim of fostering a sense of self-confidence, such as not being awkward, embarrassed, insecure about one's shortcomings, so that music playing activities can be done happily. The process of training for music and church organs is carried out by means of teaching methods both orally and in theory, which are applied through methods of education, training and mentoring. Through both oral teaching methods, theory and practice (demonstration) in this training activity was considered quite successful. Success indicators can be seen and evaluated through small performances carried out jointly by the music team with a song lieder in the last activity carried out in the training.
\end{abstract}

Keywords: Organ, Church Music, Individual, Collective

Correspondence author: Ance Juliet Panggabean, ance.panggabean@uhn.ac.id, Medan, Indonesia

\section{PENDAHULUAN}

\section{Latar Belakang Masalah}

Gereja Huria Kristen Batak Protestan atau yang disingkat dengan HKBP merupakan gereja dalam setiap ibadahnya kita melihat dan mendengar nyanyian dari buku Ende HKBP dan musik yang dimainkan menggunakan alat musik organ gereja 
(dalam bahasa Bataknya Poti Marende). Saat ini, sering kita jumpai kebaktian atau ibadah tidak hanya diiringi oleh musik organ namun dengan musik tiup. Seiring dengan perkembangan jaman, musik ibadah juga turut mengalami perubahan dengan penggunaan dan kolaborasi alat musik tradisional dan alat musik modern. Sekarang ini, musik organ gereja hampir terlupakan atau terabaikan dengan hadirnya musik box yang digunakan dalam ibadah gereja HKBP. Perkembangan musik dalam ibadah gereja HKBP telah mengalami perubahan oleh karena perkembangan teknologi dan informasi khusus dalam nyanyian dan musik ibadah dari gereja-gereja sekitar HKBP.

Perubahan musik ibadah yang modern yang terjadi di gereja HKBP dapat dilihat melalui penggunaan alat musik dan nyanyian rohani popular. Musik organ dan pemain organ (organist) dengan penggunaan buku logu dari sejak awal digunakan dalam ibadah gereja HKBP sudah bergeser kedudukannya dianggap sudah kurang semangat dan meriah serta monoton. Perubahan ini pasti dilandasi dengan pertimbangan-pertimbang pihak gereja terkait, sehingga dapat diteriam oleh warga gereja HKBP.

Untuk menjaga kelestarian dan memupuk kecintaan terhadap musik organ gereja HKBP sebagai pengiring ibadah dalam gereja HKBP, Biro Ibadah dan Musik Kantor Pusat HKBP Pearaja Tarutung dalam misinya melakukan atau mengadakan kegiatan rutin pelatihan musik organ gereja dan song lieder dua sampai tiga kali dalam setahun.

\subsection{Identifikasi dan Perumusan Masalah}

Berdasarkan latar belakang masalah diatas, maka dapat dirumuskan permaslahan yaitu bagaimana melatih musik dan organ gereja HKBP yang lebih mudah dan menarik?

\subsection{Tujuan Pengabdian}

Adapun tujuan dibagi dalam tujuan umum dan tujuan khusus, yaitu:

Tujuan Umum:

1. Memberikan wawasan dan pengetahuan mengenai cara mudah bermain organ gereja bagi jemaat

2. Memberikan wawasan dan pengetahuan cara mudan mempelajari buku logu HKBP jemaat

Tujuan Khusus: 
Setelah selesai pelatihan diharaapkan kepada tim musik memiliki wawasan tentang cara mudah memainkan organ gereja dengan menggunakan buku logu HKBP dan menerapkannya guna meningkatkan teknik permainan atau skill musik khususnya organ gereja.

\subsection{Manfaat Pengabdian}

Manfaat yang diharapkan dalam pengabdian masyarakat ini, adalah:

1. Memotivasi tim musik melakukan kegiatan mengiringi musik ibadah gereja dilingkungan HKBP

2. Meningkatkan kualitas dan kuantitas karya pengembangan dan peningkatan skill/kemahiran dalam bermain organ gereja dalam ibadah gereja HKBP

3. Meningkatkan pengetahuan dan wawasan dalam bermain organ gereja bagi tim musik.

\section{TINJAUAN PUSTAKA}

1. Pengertian Musik

Menurut Syafiq (2003: 203) musik didefinisikan sebagai seni yang mengungkapkan gagasan melalui bunyi yang unsur dasarnya berupa melodi, irama dan harmoni, dengan unsur pendukung berupa bentuk gagasan, sifat serta warna bunyi. Dalam penyajianya sering berpadu dengan unsur-unsur lain seperti bahasa, gerak ataupun suara. Musik juga memiliki arti seperti yang ditulis di Kamus Besar Bahasa Indonesia (2002: 766) yaitu nada atau suara yang disusun sedemikian rupa sehingga mengandung irama, lagu dan keharmonisan (terutama yang menggunakan alat-alat yang dapat menghasilkan bunyi).

Menurut Banoe (2003:288) musik adalah cabang seni yang membahas dan menetapkan berbagai suara kedalam pola-pola yang dapat dimengerti dan dipahami manusia. Banoe juga mengungkapkan musik berasal dari kata muse, yaitu salah satu dewa dalam mitologi Yunani kuno bagi cabang seni dan ilmu, dewa seni dan ilmu pengetahuan. Dalam pembentukan musik secara utuh unsur-unsur dan struktur musik mempunyai paranan penting dan keterkaitan yang kuat antara satu dengan yang lainya.

1. Melodi

Melodi adalah susunan rangkaian nada (bunyi dengan getaran teratur) yang terdengar berurutan serta berirama dan mengungkapkan suatu gagasan atau 
ide (Jamalus, 1988:16). Dalam hal ini, melodi memiliki pengertian nada-nada pokok tema lagu tersebut diluar nada-nada iringan.

2. Irama

Irama adalah pola ritme tertentu yang dinyatakan dengan nama, seperti Walz, March, Bosanova dan lain-lain (Banoe 2003:138). Secara umum irama dapat diartikan sebagai gerakan berturut-turut secara teratur, turun naik lagu atau bunyi yang beraturan (Kamus Bahasa Indonesia, 2008: 598).

3. Harmoni

Harmoni merupakan perihal keselarasan bunyi. Secara teknis meliputi susunan, peranan dan hubungan dari sebuah paduan bunyi dengan sesamanya atau dengan bentuk keseluruhannya (Syafiq, 2003: 133).

\section{Organ Gereja}

Pengertian organ gereja adalah organ termasuk alat musik yang terbilang tua. Sejak abad pertengahan hingga perkembangan gereja Protestan, organ merupakan instrumen yang paling dominan untuk mengiringi lagu-lagu kristiani. Sebaliknya, lagu-lagu Kristiani pada saat itu pun diciptakan dalam nuansa yang memang dirancang untuk organ. Organ memiliki suara yang khas. Suara khas yang merambat melalui pipa pada organ memang menjadikannya sebagai pengisi besar dalam kebanyakan lagu-lagu gereja yang dinyanyikan paduan suara bersama jemaat. Nuansa yang ditimbulkan memberi kesan megah dan syahdu sehingga sangat cocok dengan nuansa yang hendak dibangun oleh lagu pujian Kristiani. (Selisip, 2019:1) https://selisip.com/2019/10/organ-sebagai-alat-musik-gereja/ diakses Selasa, 29 September 2020)

Dewasa ini, penggunan organ di gereja-gereja memang semakin berkurang seiring dengan perkembangan musik gerejawi yang lebih modern. Peran organ cukup banyak digantikan oleh keyboard atau piano ayng lebih mudah untuk digunakan dan lebih praktis.

Menurut Pasaribu, 2018 bahwa pada saat Missionaris German datang ke Tanah Batak tahun 1861dan mendirikan Gereja Mision Batak (GMB) yang sekarang menjadi HKBP; mereka memperkenalkan injil dengan cara berkhotbah dan bermusik. Alat musik yang digunakan adalah Organ atau yang disebut Poti Marende. Organ 
atauPoti Marende dibunyikan dengan cara seperti mendayung sepeda, kemudian keluarlah bunyi merdu dari organ tersebut. Seiring dengan perkembangan jaman, Poti Marende tidak dipakai lagi dan perannya digantikan.

Organ/electone

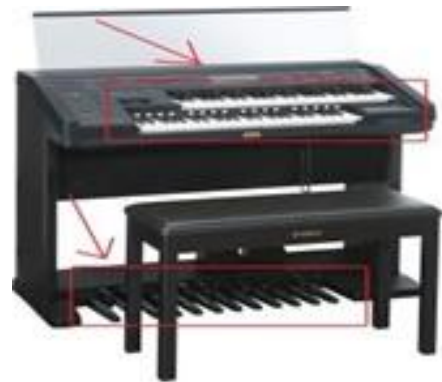

Gambar 1.Organ / Elektone dan Keyboard
Keyboard

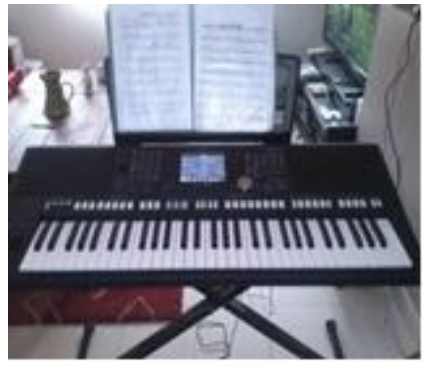

\section{METODE PELAKSANAAN}

Sebagai solusi dari permasalahan yang dihadapi mitra dalam pelatihan musik dan organ gereja di Siborong-borong, maka dilakukan beberapa metode pendekatan, yaitu:

1. Menjelaskan kepada mitra metode pengajaran kepada jemaat dan tim musik, yaitu dengan menunjukkan sikap apresiatif terhadap cara mudah bermain organ gereja dengan menggunakan buku logu HKBP.

2. Menjelaskan kepada mitra tentang cara mudah membaca notasi balok dengan menggunakan referensi buku logu HKBP bagi jemaat dan tim musik agar memperoleh suara musik yang harmonis yang dihasilkan dari nada-nada yang dimainkan pada organ secara baik.

3. Menjelaskan kepada mitra bahwa melakukan pemilihan repertoar lagu gereja dan perlunya dilakukan latihan terhadap lagu yang rumit sebelum tampil mengiringi dalam ibadah terlebih dahulu bersama song lieder (pemimpin nyanyian). Tujuannya agar dapat memudahkan tim musik dan song lieder dalam membawakan secara harmonis, baik dan benar.

4. Memberikan pelatihan skill kepada mitra tentang teknik bermain organ, teknik membaca buku logu dan teknik penjiwaan lagu. Melalui kegiatan ini diperlukan pelatihan dan pendampingan kepada tim musik oleh pelatih.

5. Memberikan pelatihan dan pendampingan bagi tim musik dalam memainkan buku logu pada alat musik organ. Memberikan pendidikan, pelatihan skill, dan 
pendampingan,cara bermain organ secara individu dan kolektif kepada tim musik.

Metode pendidikan, pelatihan skil, dan pendampingan ini dilakukan di kantor Distric XVI Humbang Habinsaran Siborong-borong selama dua hari, Rabu sampai dengan hari Kamis tanggal 25 dan 26 September 2019 mulai pukul 08.00 WIB sampai dengan 17.00 WIB. Pada kegiatan pelatihan musik dan organ gereja, para peserta diwajibkan membawa alat musik masing-masing seperti keyboard (paling praktis untuk dibawa) tujuannya agar memudahkan para peserta beradaptasi dalam pengguaan alat musik yang mereka mainkan. Biro ibadah dan musik HKBP juga turut berperan serta dalam mempersiapkan sarana dan pra sarana untuk kelancaran kegiatan pelatihan tersebut di Siborong-borong.

Sasaran atau mitra dari kegiatan ini dipilih dari tim pemain musik setiap resort gereja yang ada di Humbang Habinsaran Siborong-borong dan song lieder. Pemilihan mitra ini dilakukan untuk mendapatkan komitmen dari mitra mau dan bersedia mengikuti pertemuan dan pelatihan serta memiliki keinginan yang kuat untuk melanjutkan kegiatan pelatihan tanpa pendampingan oleh pelatih/tim dari FBS Universitas HKBP Nommensen Medan.

Metode yang digunakan adalah metode pendidikan, pendampingan dan pelatihan untuk kegiatan pelatihan musik dan organ gereja menjadi suatu kegiatan yang menyenangkan bagi pemain musik (tim musik). Mula-mula mitra diberikan penjelasan bahwa pelatihan musik dan organ gereja ini memberikan manfaat dan keuntungan bagi mereka. Tim menyadari sepenuhnya, bahwa teori atau penjelasan secara lisan yang diberikan tim kepada mitra harus diikuti dengan kegiatan praktek dalam bentuk pelatihan agar hasil atau sasaran tujuan tercapai dengan baik. Oleh karena itu, setelah tim memberi teori atau penjelasan tentang kegiatan bermain organ dengan teknik yang baik dan benar lalu dilanjutkan pelatihan dan pendampingan oleh tim. Materi pemberian teori dan pelatihan pada kegiatan tersebut, antara lain:

1. Buku Logu no 421, Amen Amen

2. Buku Logu no 422, Halleluyah

3. Buku Logu no 423, Ai Ho Do

4. Buku Logu no 73, Ndang Tadingkonhonku Ho

5. Buku Logu no 716, Dina Mamolus Sandok Ngolu On 
6. Buku Logu no. 322 Nda da Au Guru Di Au

7. Buku Logu no. 210 Raja na Tumimbul

8. Buku Logu no. 224 Ho Sipangolu AuBuku Logu no. 585 Sombama Jahowa

\section{HASIL DAN PEMBAHASAN}

Secara umum seluruh kegiatan yang terangkai dari awal sampai akhir kegiatan dapat terlaksana dengan baik sesuai dengan rencana. Jika ada masalah atau kendala yang dihadapi, hal tersebut hanya menjadi masalah teknis. Misalnya, ketidak sesuaian waktu antara tim dengan mitra untuk melakukan pertemuan atau pelatihan. Dari beberapa rangkaian kegiatan yang termasuk di dalam laporan ini adalah:

1. Kegiatan pelatihan ini ditentukan tempat pelaksanaan Abdimas dipilih kantor distric XVI HKBP Humbang Habinsaran Siborong-borong. Alasan pemilihan lokasi adalah: lokasi tersebut dekat dengan lokasi peserta pelatihan. 2. Biro Ibadah dan Musik HKBP Pusat Pearaja Tarutung berperan serta dalam memotivasi peserta pelatihan.

2. Pelaksanaan kegiatan pelatihan musik dan organ gereja dilakukan berdasarkan metode pendekatan pendidikan, pelatihan dan pendampingan.

3. Metode pendidikan; tim melakukan metode pendidikan melalui penjelasan tentang:

Pada dasarnya bermain organ itu tidak susah, apabila kita berdoa, serius, sabar, dan tidak mudah pantang menyerah, sekaligus didasari niat untuk memberikannya kembali untuk kemuliaan Tuhan.

Motivasi pelayanan untuk bidang musik di gereja akan mendorong kita untuk mengalokasikan waktu belajar memainkan alat musik yang dibutuhkan sesuai dengan situasi dan kondisi di mana kita berada. Hal-hal dasar yang diajarkan dan dilatih, sebagai berikut:

\section{POSISI DALAM BERMAIN ORGAN/KEYBOARD}

Dalam teknik dasar bermain ORGAN/KEYBOARD, untuk melatih jari jari disebut fingering (melatih kemampuan/kelenturan/kecekatan/kekuatan jari jari) hal yang penting diperhatikan pemain adalah:

1. Posisi tangan dan Letak jari jari pada tuts organ/keyboard

2. Posisi duduk

3. Kekuatan jari jari dan perbedaan panjang jari jari kita 
4. Ketekunan dan disiplin dalam berlatih.

\section{TEKNIK DALAM BERMAIN KEYBOARD :}

1. Memahami simbol jari tangan kanan dan notasi pada keyboard untuk bisa memainkan melodi lagu dengan baik menggunakan tangan kanan.

2. Untuk bisa mengiringi lagu dengan baik, memahami simbol jari tangan kiri dan chord.

3. Bagi yg baru belajar, sebaiknya mencoba memainkan lagu sederhana, yg iringan musiknya hanya memerlukan 2 atau 3 chord.

4. Melatih diri secara bertahap. Memainkan melodi lagu terlebih dulu dengan tangan kanan tanpa iringan. Kemudian, memainkan iringan chord dengan tangan kiri tanpa melodi. Jika sudah lancer, mencoba memainkan melodi (tangan kanan) dan chord iringan (tangan kiri) sekaligus.

5. Sangat di anjurkan agar memiliki koleksi lagu-lagu yang ditulis dengan notasi angka. Sebelum bermain, lihatlah nada dasar yang tercantum. Selanjutnya, notasi angka tersebut dimainkan dengan notasi huruf (not balok) seperti yang telah diterangkan pada bagian notasi keyboard.

8. Untuk mengiringi nynayian, tangan kiri tetap memainkan bass/chord, sedangkan tangan kanan mencipta melodi (boleh diimprovisasi jika sudah mahir) yang sesuai dengan chord dan tema lagu yang dinyanyikan. Kemampuan seperti ini memerlukan latihan sendiri. Namun tetap mengacu pada buku lo

\section{BELAJAR KUNCI DASAR ORGAN MENGGUNAKAN NADA NADA HARMONI}

Ada 2 macam sebenarnya cara memainkan organ:

1. Pada alat musik organ. Kalau kita memakai organ yang terdapat pedal kaki sebagai bass, maka kita akan mempraktekkan cara diatas pada alat musik organ.

2. Pada alat musik keyboard. Kalau yang kita pakai keyboard maka akan sedikit berbeda. Pada tangan kiri kita hanya perlu memprogram supaya output bass. Jadi ketika sudah diprogram maka, tangan kiri kita hanya perlu menekan satu nada saja berupa nada do (1). Tapi nada tersebut tidak sembarangan ditekan, melainkan menyesuaikan dengan chord yang harusnya ditekan

\section{PROSEDUR DALAM BERMAIN ORGAN / KEYBOARD:}


Penting untuk Diperhatikan:

1. Aturanjaritanganpada organ/keyboard,

2. Belajar organ/keyboard untukpemula atau sudah mahir

3. Belajar akor dasar, kuncidasar, harmoni, kuncikunc

yang seringdigunakan, penerapanjarijaritanganpadatuts organ/keyboard, posisi jari tangan pada organ/keyboard yang benar.

\section{BELAJAR NOTASI BALOK}

Belajar Not Balok :

- Inti dari belajar alat musik adalah apabila kita dapat menguasai notasi balok. Begitu halnya bermain organ, mustahil kita dapat bermain organ kalau kita belum bisa membaca not balok. Inilah yang membuat orang banyak mundur untuk belajar bermain organ. Hal ini didasari dalam ilmu pendidikan kita memang kurang menekankan belajar not balok melainkan lebih ke not angka.

\section{TANDA KUNCI}

- Didalam notasi balok dan didalam Buku Logu kunci yang umumnya digunakan adalah kunci "G" dan kunci "F". Kunci $G$ atau kunci Biola yaitu not yang terletak pada garis no 2 dari bawah pada tangga nada, sedangkan Kunci $\mathrm{F}$ atau sering disebut kunci Bass terletak pada garis no 2 dari atas tangga nada. Contoh:

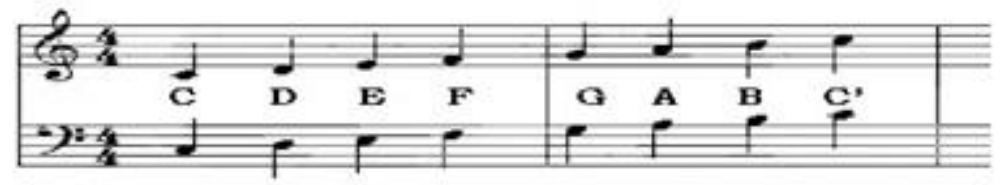

Gambar 2, tanda kunci G dan Kunci F

\section{BUKU LOGU}

- Dalam Buku Logu kita akan melihat Kunci G dan F tampil secara bersamaan. Dalam Kunci G dan F sama-sama terdapat not balok ganda yang saling berhimpitan dan bertolak belakang, satu keatas dan satu lagi mengarah kebawah. Pada kunci $G$ not yang mengarah keatas adalah not sopran, dan yang kebawah adalah alto. Pada Kunci $\mathrm{F}$ not yang mengarah keatas adalah not tenor, dan yang mengarah kebawah adalah bass. Bagi saudara yang baru belajar mungkin agak sulit melihat 4 not secara bersamaan, namun saudara bisa memulainya satu persatu dan bertahap. Disinilah letak kesulitannya..tapi 
yakinlah dengan ketekunan saudara dan latihan yang berkesinambungan serta kekuatan dari Tuhan, saudara pasti dapat melakukannya.

Materi pemberian teori dan pelatihan pada kegiatan tersebut, antara lain:

$>$ Buku Logu no 421, Amen Amen

$>$ Buku Logu no 422, Halleluyah

$>$ Buku Logu no 423, Ai Ho Do

> Buku Logu no 73, Ndang Tadingkonhonku Ho

> Buku Logu no 716, Dina Mamolus Sandok Ngolu On

$>$ Buku Logu no. 322 Nda da Au Guru Di Au

$>$ Buku Logu no. 210 Raja na Tumimbul

> Buku Logu no. 224 Ho Sipangolu Au

$>$ Buku Logu no. 585 Sombama Jahowa

\section{MENCARI NADA KREIS $(\#)$}

- $\quad$ Kreis adalah naik $1 / 2$ nada yaitu nada ke 5 (lima) menjadi nada dasar dan nada kez (tujuh) berubah menjadi Kreis.

- Netral $=\mathbf{C}-\mathrm{D}-\mathrm{E}-\mathrm{F}-\mathrm{G}-\mathrm{A}-\mathrm{B}-\mathrm{C} \quad($ Nada dasar $\mathrm{C}=1)$

- 1 Kreis $=\mathbf{G}-\mathrm{A}-\mathrm{B}-\mathrm{C}-\mathrm{D}-\mathrm{E}-\boldsymbol{F i s}-\mathrm{G} \quad(\mathrm{G}=1)$ yg berubah $\boldsymbol{F i s}$

- 2 Kreis $=\mathrm{D}-\mathrm{E}-\boldsymbol{F i s}-\mathrm{G}-\mathrm{A}-\mathrm{B}-\boldsymbol{C} \boldsymbol{i s}-\mathrm{D} \quad(\mathrm{D}=1)$ yg berubah Fis, Cis

- $\quad 3$ Kreis $=\mathrm{A}-\mathrm{B}-\boldsymbol{C} \boldsymbol{i s}-\mathrm{D}-\mathrm{E}-\boldsymbol{F i s}-\boldsymbol{G i s}-\mathrm{A}(\mathrm{A}=1)$ yg berubah Fis, Cis, Gis

- 4 Kreis = E - Fis - Gis $-\mathrm{A}-\mathrm{B}-\boldsymbol{C i s}-\boldsymbol{D i s}-\mathrm{E}(\mathrm{E}=1)$ yg berubah Fis, Cis,

\section{Gis, Dis}

- 5 Kreis = B - Cis - Dis $-\mathrm{E}-\boldsymbol{F i s}-\boldsymbol{G i s}-\boldsymbol{A i s}-\mathrm{B}(\mathrm{B}=1)$ yg berubah Fis, Cis,

Gis, Dis, Ais

\section{MENCARI NADA MOL $\left({ }^{b}\right)$}

- Mol adalah kebalikannya Kreis atau turun $1 / 2$ nada yaitu nada ke 4 (empat) menjadi nada dasar dan nada ke 4 (empat) juga berubah menjadi Mol.

- $\quad$ Netral $=\mathbf{C}-\mathrm{D}-\mathrm{E}-\mathrm{F}-\mathrm{G}-\mathrm{A}-\mathrm{B}-\mathrm{C} \quad($ Nada dasar $\mathrm{C}=1)$

- $\quad 1 \mathrm{Mol}=\mathrm{F}-\mathrm{G}-\mathrm{A}-\boldsymbol{B e s}-\mathrm{C}-\mathrm{D}-\mathrm{E}-\mathrm{F} \quad(\mathrm{F}=1)$ yg berubah $\boldsymbol{B e s}$

- $\quad 2 \mathrm{Mol}=\boldsymbol{B e s}-\mathrm{C}-\mathrm{D}-\boldsymbol{E s}-\mathrm{F}-\mathrm{G}-\mathrm{A}-\boldsymbol{B e s}($ Bes=1) yg berubah Bes, Es

- $\quad 3 \mathrm{Mol}=\boldsymbol{E} \boldsymbol{s}-\mathrm{F}-\mathrm{G}-\boldsymbol{A s}-\boldsymbol{B e s}-\mathrm{C}-\mathrm{D}-\boldsymbol{E s}(\mathrm{Es}=1)$ yg berubah Bes, Es, As 
- $4 \mathrm{Mol}=\boldsymbol{A s}-\boldsymbol{B e s}-\mathrm{C}-\boldsymbol{D e s}-\boldsymbol{E s}-\mathrm{F}-\mathrm{G}-\boldsymbol{A s}(\mathrm{As}=1)$ yg berubah Bes, $\boldsymbol{E} \boldsymbol{s}$, As, Des

- $\quad 5 \mathrm{Mol}=$ Des $-\boldsymbol{E s}-\mathrm{F}-\boldsymbol{G e s}-\boldsymbol{A s}-\boldsymbol{B e s}-\mathrm{C}-$ Des $($ Des=1) yg berubah $\boldsymbol{B e s}$, Es, As, Des, Ges

10. MENGAPLIKASIKAN KE ORGAN/KEYBOARD (POTI MARENDE)

- Penting dalam bermain organ, saudara harus benar-benar hafal nada2 apa saja yang berubah dalam Kreis ataupun Mol. Karena itulah dasar yang akan saudara terapkan dalam prakteknya. Setelah saudara mengetahui semua teori diatas, saatnya saudara praktekkan kedalam tuts organ.

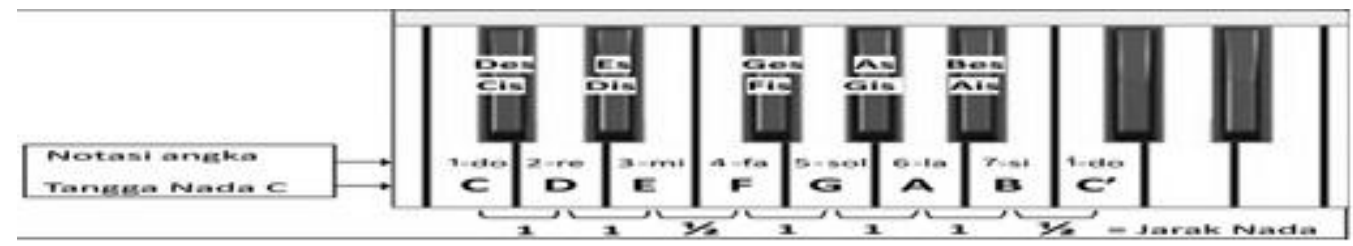

Gambar 3. Huruf Abjact Yang Terdapat Pada Notasi Balok

Untuk semakin memudahkan saudara dalam mengaplikasikan teori diatas ke organ berikut contohnya:

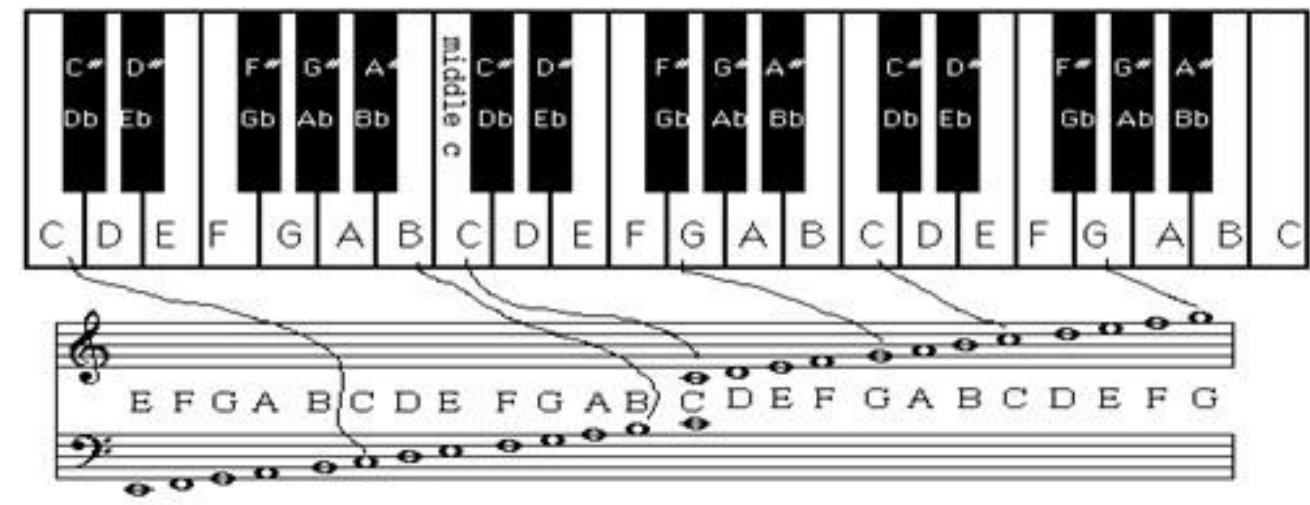

Gambar 4. Nada-Nada Yang Terletak Pada Kunci G Dan Kunci F Notasi Balok 


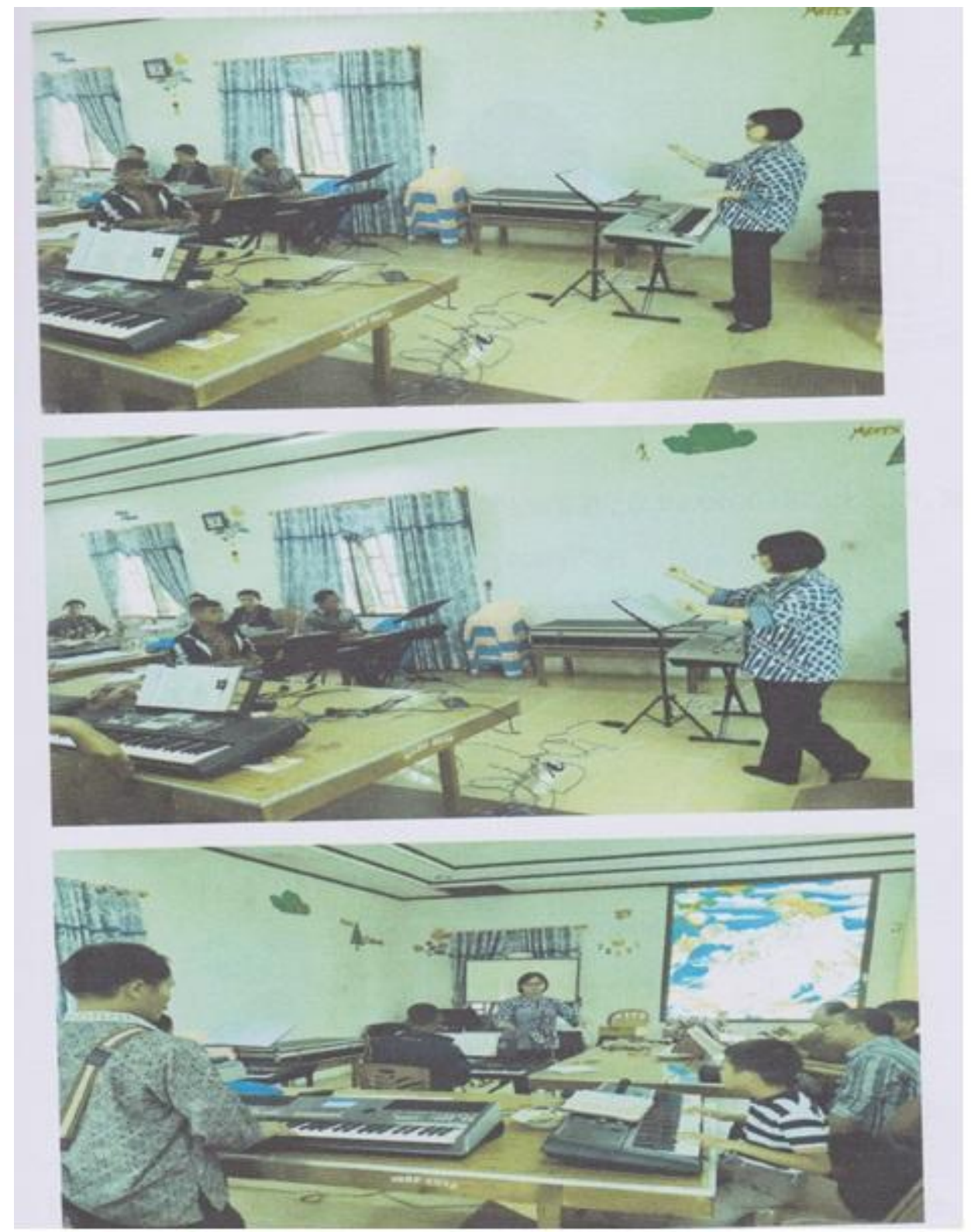

Gambar 5. Kegiatan Pelatihan Dalam Gambar/Foto: 
DAFTAR HADIR PESERTA

PELATIHAN MUSIK IBADAH DAN SONG LIEDER

'CARA MUDAH BERMAIN ORGAN GEREJA (POTI MARENDE)

BAGI ORGANIS GEREJA DI SIBORONG-BORONG'

\begin{tabular}{|c|c|c|c|c|}
\hline No & NAMA & JABATAN & TANDATANGAN & KETERANGAN \\
\hline 1. & Cst V.MAlau & & Why & \\
\hline 2 & Xagan $y$ Xutasoit & & rems & \\
\hline 3 & DAVID H SIIYBOROIY & & & \\
\hline 4 & RUTMAN SINAMEELA & & & \\
\hline 5 & MARTIN. L. SIMAMIORA & & tha & \\
\hline 6 & Christian Manullan \& & & Sprostims & \\
\hline 7. & MARAN ATHA SIMNGUNSON & & Nawio. & \\
\hline 8 & Findang fihonbin & & & \\
\hline
\end{tabular}

\section{DAFTAR HADIR PESERTA}

PELATIHAN MUSIK IBADAH DAN SONG LIEDER

'CARA MUDAH BERMAIN ORGAN GEREJA (POTI MARENDE)

BAGI ORGANIS GEREIA DI SIBORONG-BORONG'

\begin{tabular}{|c|c|c|c|c|}
\hline No & NAMA & JABATAN & TANDATANGAN & KETERANGA \\
\hline 1 & MAKARIOS SIHOMBING & & & \\
\hline 2 & HITLER PURBA & & & \\
\hline 3 & SL JANUARI HUTASOIT & & & \\
\hline 4. & sx. Zuares Simarquariste & & $\mu_{10}$ & \\
\hline 5. & 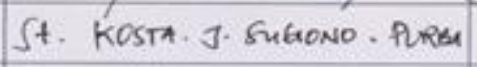 & & simplo. & \\
\hline 6 & MARTIN.L. SIMAMORA & & Metet & \\
\hline 7 & RLITMAN SINAMBELLA & & & \\
\hline 8 & Christian Manullang & & Chrituen & $<$ \\
\hline 9 & Toush Ohwila Sutassot. & & & \\
\hline 10 & Hagan Y bhtasait & & 6 & \\
\hline 11 & DAVID it simbelon & & Ques & \\
\hline 12 & Cst V. MAlan. spd & & $\Delta t>$ & \\
\hline
\end{tabular}


Gambar 6. Daftar Peserta Hadir

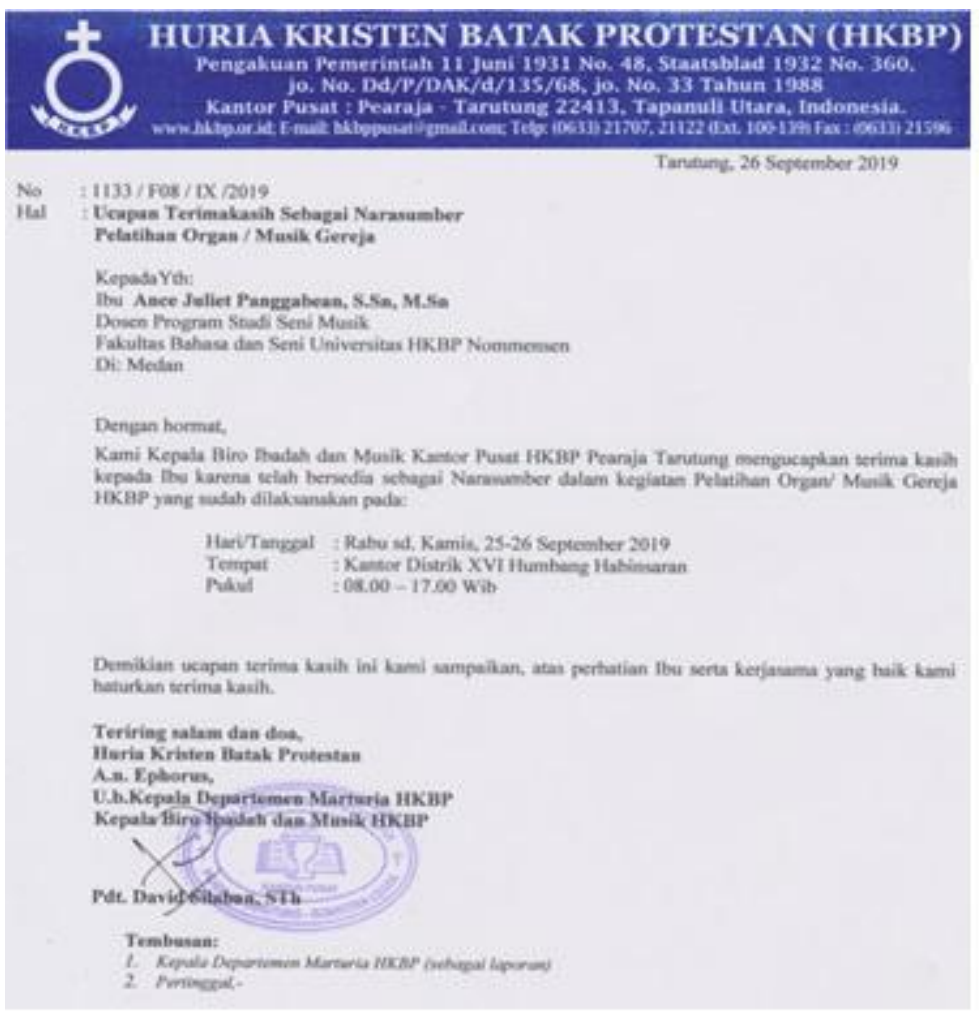

Gambar 7. Surat Ucapan Terima kasih 


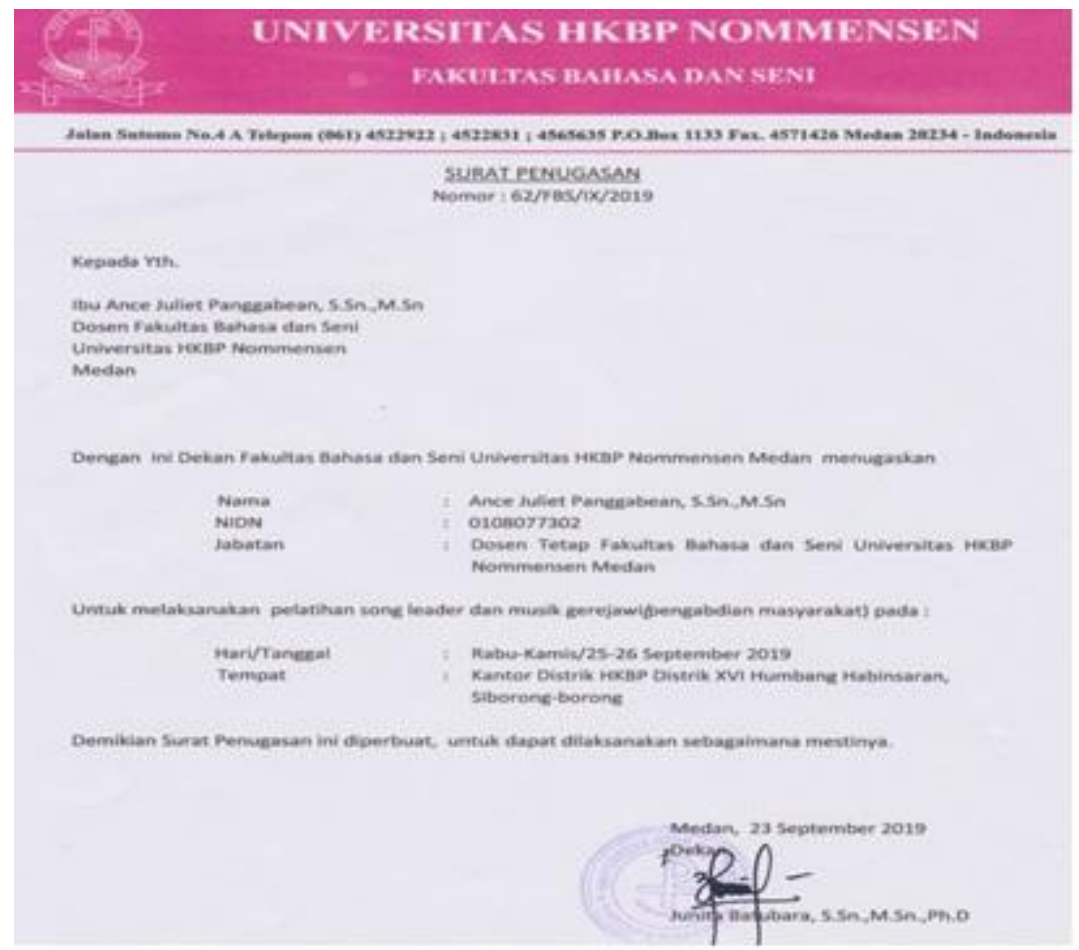

\section{Gambar 8. Surat Penugasan}

\section{KESIMPULAN}

Terlaksananya kegiatan pelatihan musik gereja dan organ gereja memberi kepuasan tersendiri bagi jemaat terkhusus bagi tim musik yang melayani sebagai pengiring musik dalam ibadah gereja. Kegiatan pelatihan musik gereja dan organ gereja sangat membantu para tim musik dalam bermain organ gereja dengan cara mudah dan praktis.

Penggunaan buku logu dan pembacaan notasi balok sangat fleksibel untuk diterapkan dalam iringan lagu ibadah digereja karena menghasilkan suara yang harmonis.

Penjiwaan lagu dalam iringan ibadah di gereja HKBP dalam bermain musik gereja dan organ gereja sangat baik diterapkan tujuannya untuk menambah syahdu dan hikmat dari lagu-lagu yang dimainkan dalam ibadah.

\section{DAFTAR PUSTAKA}

Banoe, Pono. 2003.,Kamus Musik. Yogyakarta: Kanisius

Departemen Pendidikan Indonesia (2008). Kamus Besar Bahasa Indonesia. Jakarta: Balai Pustaka. 
Jamalus. 1988., Pengajaran Musik Untuk Melalui Pengalaman Musik, Jakarta: Departemen Pendidikan dan Kebudayaan.

Kantor Pusat HKBP Pearaja Tarutung 2009., Buku Logu HKBP Suplemen Kantor Pusat HKBP Pearaja Tarutung, Cetakan ke 10. ISBN 978-979-98792-8-8. HAK CIPTA HKBP. Pematang Siantar; Percetakan HKBP.

KBBI (kamus Besar Indonesia), 2002.,Kamus Besar Bahasa Indonesia (Edisi Ketiga), Jakarta: Balai Pustaka.

Syafiq, Muhammad. 2003.,Ensiklopedia Musik Klasik, Yogyakarta: Adicita Karya Nusa.

\section{Sumber Internet:}

Sinaga Eko, 2010.,Cara Mudah Belajar Main Organ Gereja (Poti Marende), (https://ekosinaga.wordpress.com/2010/05/18/musik-gerejawi-cara-mudahbelajar-main-organ-gereja-poti-marende-2/)

Selisip, 2019.,Organ Sebagai Alat Musik Gereja, (https://selisip.com/2019/10/organsebagai-alat-musik-gereja).

Pasaribu, Naomi.2017, Musik Gereja Dari Sudut Pandang Theologia HKBP, (http://www.magisterseniusu.com/uploads/1/8/0/0/1800340/naomipasaribu.pdf). 